\title{
Burocracia e políticas públicas: implementação da Política Nacional de Humanização dos Serviços de Saúde em Porto Alegre/RS
}

Luciana Leite Lima

Universidade Federal do Rio Grande do Sul (UFRGS)

Luciano D'Ascenzi

Agência Estadual de Regulação dos Serviços Públicos

Delegados do Rio Grande do Sul

Gianna Vargas Salgado Dias

Universidade Federal do Rio Grande do Sul (UFRGS)

Renata Bruscatto

Universidade Federal do Rio Grande do Sul (UFRGS)

Este estudo analisou a implementação da Política Nacional de Humanização nas unidades básicas de saúde de Porto Alegre. Centramos a análise no uso da discricionariedade pelos atores responsáveis pela implementação. Interessou investigar como suas decisões e ações contribuíram para a adaptação da política pública e, consequentemente, seu redesenho. Averiguou-se que os implementadores, diante da falta de treinamento nos marcos da política, da percepção de carência de recursos e do baixo grau de apoio, forjaram um entendimento peculiar dos objetivos e das estratégias da política pública. Eles criaram uma visão do que seria "humanizar" os serviços ajustada às preferências e necessidades locais. A política implementada diferiu da política formal. Contudo foi essa adaptação que permitiu a implementação de fato.

Palavras-chave: burocracia, políticas públicas, discricionariedade, implementação, política social

Artigo recebido em novembro de 2013. Versão final em julho de 2014. 
Burocracia y políticas públicas: la implementación de la Política Nacional de Humanización de los Servicios de Salud en Porto Alegre/RS

Este estudio analizó la implementación de la Política Nacional de Humanización en las unidades básicas de salud de Porto Alegre. Centramos el análisis en el uso de la discricionariedad por los actores responsables por la implementación. Interesó investigar como sus decisiones y acciones contribuyeron para la adaptación de la política pública y, consecuentemente, su rediseño. Se averiguó que los implementados, delante de la falta de entrenamiento en los marcos de la política, de la percepción de carencia de recursos y del bajo grado de apoyo, forjaron un entendimiento peculiar de los objetivos y estrategias de la política pública. Ellos criaron una visión de lo que seria "humanizar" los servicios ajustada a las preferencias y necesidades locales. La política implementada diferió de la política formal. Sin embargo, fue esa adaptación que permitió la implementación de hecho.

Palabras clave: burocracia, políticas públicas, discricionariedad, implementación, política social

\section{Bureaucracy and public policy: the implementation of the National Policy of Humanization in basic health units in the city of Porto Alegre (Brazil)}

This study examined the implementation of the National Policy of Humanization in basic health units in the city of Porto Alegre (Brazil). We focus the analysis on the use of discretion by the actors responsible for implementation. It was our interest to investigate how their decisions and actions contributed to the adaptation of public policy and, consequently, its redesign. Given the lack of training in the framework of the policy, the findings show that the implementers' perception of shortage of resources and low level of support, forged a unique understanding of the goals and strategies of the public policy. They created a vision of what would be "to humanize" services, tailored to local preferences and needs. The implemented policy differed from formal policy. However, the implementation of the policy was made possible precisely due to this adaptation.

Keywords: bureaucracy, public policy, discretion, implementation, social policy 


\section{Introdução ${ }^{1}$}

A implementação de políticas públicas é um campo de estudos bastante desenvolvido internacionalmente (SAETREN, 2005, 2014), mas ainda incipiente no Brasil (FARIA, 2012; LotTA, 2012a). Uma abordagem analítica de destaque nessa área dá primazia para a discricionariedade dos atores responsáveis pela implementação, centrando-se no seu exercício e na produção de rotinas organizacionais informais que efetivamente constituem a política na base (LIPSKY, 1980; BRODKIN, 2011).

Nosso trabalho se insere nessa área. Este artigo tem por objetivo analisar a implementação da Política Nacional de Humanização (PNH) em 25 das 45 unidades básicas de saúde (UBS) de Porto Alegre ${ }^{3}$. Especificamente, centraremos nossa atenção no uso da discricionariedade pelos atores responsáveis pela implementação da política. Interessa investigar como suas decisões e ações contribuem para a adaptação da política pública e, consequentemente, seu redesenho.

Assumimos, com isso, em consonância com outros (Gofen, 2014; Brodkin, 2011; TUMmers, 2011; LotTA, 2012b), que as decisões e ações dos atores de linha de frente, que executam as políticas públicas em interação direta com o cidadão, divergem das intenções dos formuladores. Com isso, mudam a trajetória da política, influenciando seus resultados e impactos.

Para operacionalizar esse intento, escolhemos a implementação da PNH, principalmente por ser uma iniciativa formulada no Governo Federal, mas cuja operacionalização depende dos municípios. O Sistema Único de Saúde funciona de forma descentralizada, tendo os municípios um papel importante na oferta de serviços; tanto é que a descentralização da saúde no Brasil ficou conhecida como municipalização.

Embora os municípios tenham autonomia para gerir o sistema de saúde em seu território, encontram dificuldades para desenvolver capacidades de formulação e financiamento de políticas. Nos anos 1990, o Ministério da Saúde passou a atuar

\footnotetext{
${ }^{1}$ Agradecemos as sugestões e críticas dos pareceristas anônimos da Revista do Serviço Público.

${ }^{2}$ Este artigo é um dos produtos da pesquisa Implementação de políticas públicas e participação da comunidade, financiada pela Fundação de Amparo à Pesquisa do Estado do Rio Grande do Sul (FAPERGS).

${ }^{3}$ Porto Alegre é a capital do estado do Rio Grande do Sul. A cidade ocupa uma área de 496,684 km² e tem uma população de 1.409.351 habitantes, segundo o Censo Demográfico de 2010. De acordo com o Atlas do Desenvolvimento Humano no Brasil 2013, publicado pelo Programa das Nações Unidas para o Desenvolvimento, Porto Alegre ocupa a $28^{a}$ posição no ranking nacional das 50 cidades com melhor índice de desenvolvimento humano, com 0,805.
} 
como formulador e financiador, induzindo a adesão dos demais entes federados. É nesse contexto que se insere a Política Nacional de Humanização.

A PNH foi apresentada pelo Ministério da Saúde em 2003, a Secretaria Municipal de Saúde de Porto Alegre (SMS) formalizou sua adesão em 2004 e, em 2006, criou o Comitê de Humanização com o propósito de difundir e incentivar a execução da política nos serviços municipais de saúde. A partir daí, as atividades relacionadas à política de humanização deveriam ser inseridas nos relatórios de gestão das unidades de saúde. Esses relatórios são instrumentos de prestação de contas, com base nos quais são elaborados os relatórios de gestão da Secretaria de Saúde. Esses, por sua vez, são avaliados pelo Conselho Municipal de Saúde e são utilizados como ferramentas de publicização das atividades desenvolvidas pela SMS.

Este artigo está dividido em seis partes, além desta introdução. No segundo tópico, apresentamos o modelo analítico que guiou a seleção de variáveis e a análise. No terceiro, explicitamos o método. No quarto, expomos a Política Nacional de Humanização segundo as intenções de seus formuladores. Na quinta parte do artigo, descrevemos e analisamos pontualmente os dados coletados na pesquisa de campo. No sexto tópico, analisamos os dados e buscamos delinear a Política Nacional de Humanização segundo a visão de seus implementadores. Por fim, fechamos o artigo com a conclusão, que sumariza os achados.

\section{Marco analítico}

O estudo da implementação de políticas públicas se caracteriza por uma multiplicidade de abordagens analíticas e teóricas (SAetren, 2014). Contudo, Hupe (2014) demonstra que, nos trabalhos contemporâneos, a distinção analítica top-down e bottom-up ainda é largamente utilizada, embora o desenho das pesquisas tenha se sofisticado. Deve-se salientar que essa distinção não se expressa na forma de dicotomia (Hupe; HiLL; NANGIA, 2014). É uma questão de perspectiva, cuja operacionalização se dá por meio da integração de diferentes variáveis (WINTER, 2014).

As abordagens top-down assumem que a implementação das políticas deve estar em conformidade com as intenções formuladas pelas instâncias decisórias. Nesse sentido, ocorre um problema de implementação quando uma decisão política não é executada conforme foi planejada (LundiN, 2007). Nessa perspectiva, o desenho da política é uma importante variável explicativa da implementação (Lundin, 2007; MaY, 2012; Hupe; Hill; Nangia, 2014).

As abordagens bottom-up atentam para as relações interorganizacionais e para as burocracias de nível de rua. $O$ objetivo desse tipo de estudo é explicar a variação 
empírica nos produtos e resultados das políticas. Para tanto, volta a atenção para os espaços locais de execução e trata a política pública formal como uma entre diversas variáveis independentes (HUPE, 2014).

Nesse contexto analítico, nos alinhamos com as abordagens que se detêm nos espaços locais de implementação. Especificamente, focamos a discricionariedade exercida pela burocracia responsável pela implementação, como é operada e quais as consequências para o resultado e o desenho da política.

As burocracias de nível de rua são as agências nas quais os trabalhadores interagem diretamente com cidadãos no curso de suas tarefas e que têm substancial discrição na execução de seu trabalho (LIPSkY, 1980). Na literatura sobre implementação de políticas públicas, já é amplamente aceita a ideia de que a burocracia de nível de rua exerce um papel importante no processo de implementação (GoFEN, 2014; LOTTA, 2012a; LIPSKY, 1980). Esses atores promovem mudanças na política, adaptando-a aos contextos de ação, separando a política pública de fato da política pública de fiç̧ão (Gofen, 2014).

Isso ocorre por meio do exercício da discricionariedade, possível em virtude do caráter profissional da atuação, da limitação de recursos, das restrições para supervisionar e controlar as atividades e da ambiguidade de objetivos e estratégias das políticas. Nesse quadro, a discricionariedade dos burocratas de nível de rua afeta a trajetória e os resultados das políticas públicas (Gofen, 2014; LotTA, 2012a; PIRES, 2009; LIPSKY, 1980).

A discricionariedade, por um lado, é necessária, uma vez que os serviços sociais requerem respostas a circunstâncias complexas e individuais, bem como julgamentos. Por outro lado, a discrição concede controle aos agentes de linha de frente, cujas variações nas práticas podem, algumas vezes, prejudicar mais do que beneficiar a política e os cidadãos (BRODKIN, 2007).

Brodkin (2007), a partir da análise das reformas administrativas na provisão de bem-estar social nos Estados Unidos, afirma que as tentativas de controlar a discricionariedade das burocracias de linha de frente se mostraram fúteis e frustrantes. Segundo a autora, quando o trabalho é complexo e interpretativo, não é realista minimizar a discrição.

Essa ideia-força tem orientado muitos dos trabalhos no campo da análise da implementação. Com isso, já não se discute mais se há ou não discricionariedade na burocracia de nível de rua, mas como isso ocorre e quais são suas consequências para as políticas públicas no que tange à sua trajetória, aos seus resultados e, inclusive, ao seu desenho. Esforços de análise recentes demonstram esse quadro.

Da produção internacional, destacamos os seguintes trabalhos. Gofen (2014) analisou a influência da divergência, ações dos burocratas de nível de rua que vão 
contra as diretivas formais da política pública e contra as intenções de seus superiores sobre a política pública. Tummers (2011) investigou os fatores que explicam a disposição, ou a relutância, de profissionais de linha de frente, na área da saúde, para implementar novas políticas. $\mathrm{O}$ autor sustenta que, quanto maior a percepção de falta de discricionariedade durante a execução, menos suporte esses profissionais darão à política. Bastien (2009) examinou a relação entre a ambiguidade de objetivos e o uso informal da discrição.

Numa outra vertente de estudos sobre discricionariedade de burocratas de nível de rua, Soss, Fording e Schram (2011) pesquisaram como os esforços de disciplinar esses burocratas por meio de ferramentas da Nova Administração Pública conformam seus esforços para disciplinar os clientes. Os autores afirmam que o uso da discrição não ocorre de forma pontual ou incompreensível, nem reflete apenas preferências individuais, mas é modelado por rotinas, ferramentas e normas organizacionais. Nessa linha, deve-se citar o trabalho influente de Brodkin (2011), que analisa como os burocratas de linha de frente respondem aos instrumentos de incentivo ao incremento e ao controle de desempenho da Nova Administração Pública, ajustando-os por meio de sua discricionariedade, produzindo práticas informais que são muito diferentes das intenções dos formuladores.

May e Winter (2009) estudaram a influência de atores políticos, dos gestores e das disposições dos burocratas de nível de rua na conformação das ações nas linhas de frente da implementação. Os autores constataram que a influência de políticos e gestores é relativamente limitada em comparação com o entendimento que tinham os executores dos objetivos da política, seu conhecimento profissional e suas predisposições em relação à política pública.

Da produção brasileira, salientamos o trabalho de Lotta (2012b), que analisou o processo de implementação de um programa de saúde a partir da interação entre burocratas de nível de rua e usuários da política, assumindo que os resultados da política são influenciados pela forma como é implementada. Por sua vez, Pires (2009) investigou como a variação nas práticas e nas condutas de burocratas de linha de frente influencia os resultados da política de inspeção do trabalho.

Os trabalhos citados assumem que os resultados e os impactos das políticas públicas são influenciados pela forma como se dá a implementação, e tomam as práticas das burocracias executoras como ponto de partida da análise. Destacam a relevância das condições organizacionais e dos valores e visões de mundo dos atores implementadores.

Partiremos dessa visão e aceitaremos a sugestão de Hupe, Hill e Nagia (2014), de incorporar a dimensão normativa. Segundo eles, os valores expressos na estrutura normativa da política influenciam o comportamento dos atores 
responsáveis por sua tradução. Trataremos a política formal como um insumo, entre outros, que explica a performance dos implementadores (HUPE, 2014; MAY, 2012). Nesse sentido, pode-se lançar mão da ideia desenvolvida por Majone e Wildavsky (1984).

Para eles, as normas que estabelecem a política pública são entendidas como um conjunto de disposições que funcionam como ponto de partida para um processo de experimentação, de procura por uma estratégia mais bem adaptada a circunstâncias particulares (MAJONE; WILDAVSKY, 1984). Nessa concepção, os planos existem apenas como potencialidades, e sua realização depende de qualidades intrínsecas e de circunstâncias externas.

Políticas públicas surgem de ideias, e ideias são inesgotáveis. [...]. Assim como os problemas só são realmente entendidos depois de terem sido resolvidos, as implicações de uma ideia só podem ser percebidas de forma retrospectiva, após sua utilização e adaptação a variadas circunstâncias. (Majone; WiLdavsky, 1984, p. 169-170, tradução nossa).

Tratar o plano como um conjunto de disposições permite escapar da disputa sobre quem controla o processo de implementação, pois ele assume um caráter intrinsecamente descentralizado e aberto. No que se refere à medição do sucesso ou fracasso, essa concepção abre espaço para o resultado 'alcançado'. A medida de sucesso ou fracasso deve estar de acordo com o esforço de ação produzido. Restringi-la à conformidade com objetivos previamente definidos nos leva a desprezar os resultados reais da implementação. Dessa forma, o plano estimula e orienta a implementação.

Essa abordagem centra a análise nos atores dos níveis organizacionais responsáveis pela implementação, nas suas condições de trabalho e visões de mundo. Considera-se que a política muda à medida que é executada; a implementação é percebida como um processo interativo de formulação, implementação e reformulação (MAZMAniAn; SABATIER, 1983).

\section{Método}

Com base na literatura apresentada, selecionamos três grupos de variáveis independentes: conhecimento e entendimento da política pública por parte dos executores; condições organizacionais; e conformidade dos implementadores com os princípios e objetivos da política.

Por seu turno, tais variáveis foram operacionalizadas por meio das seguintes subvariáveis: 
a) conhecimento e entendimento da política pública por parte dos executores: conhecimento da política, acesso e fonte de material informativo, acesso a treinamento e entendimento dos objetivos e das estratégias da política;

b) condições organizacionais: estrutura física da unidade de saúde e a percepção sobre suficiência e qualidade dos recursos humanos;

c) conformidade dos implementadores com os princípios e objetivos da política: visão dos respondentes acerca da política pública.

Foram coletados dados primários e secundários. A coleta de dados primários foi realizada por meio de entrevistas semiestruturadas com 25 coordenadores de unidades básicas de saúde. Esses atores foram questionados sobre a implementação da Política Nacional de Humanização na unidade na qual trabalhavam.

Os coordenadores são considerados burocratas de nível de rua principalmente porque cumprem com a principal característica defendida por Lipsky (1980): interagem diretamente com os cidadãos no desenvolvimento de suas atividades. Além disso, desempenham atividades táticas e assistenciais. Entretanto o trabalho gerencial não é sua referência primária; em geral, não têm formação em gestão e constantemente se alternam entre funções gerenciais e assistenciais. Na execução dessas atividades, desenvolvem sua carreira, as consideram o coração da organização e o trabalho mais valioso. Sua posição na estrutura organizacional não é fixa e não é superior à dos demais trabalhadores. E o processo seletivo, por meio do qual acessaram o serviço público, avaliou capacidades e habilidades técnico-assistenciais.

Os burocratas em destaque nesse trabalho são profissionais da enfermagem, médicos, nutricionistas, assistentes sociais e psicólogos. A hierarquia profissional prevalece à hierarquia organizacional, assim, têm limitado espaço para interferir nas atividades de seus colegas. As relações são bastante horizontais, embora o campo da saúde seja marcado por uma hierarquia própria entre as profissões, e a ética corporativa é um elemento preponderante em suas decisões. Não é possível dizer que estão "espremidos" entre o alto escalão e o nível de rua (PIRES, 2012), já que estão empiricamente inseridos nessa última categoria ${ }^{4}$.

\footnotetext{
${ }^{4}$ Pires (2012) classifica os coordenadores como burocratas de médio escalão. Divergimos do autor. Defendemos que a categorização como burocrata de linha de frente ou de médio escalão deve se dar a partir das atividades realizadas e da matriz cognitiva que orienta o comportamento dos atores, e não unicamente de sua posição formal na hierarquia organizacional. No caso dos coordenadores das unidades básicas de saúde, a despeito de sua posição formal, suas referências e atividades estão lastreadas na assistência. Esses atores identificam-se com seus colegas e com os usuários, principalmente.
} 
O conjunto de dados secundários é composto pelas cartilhas produzidas pelo Ministério da Saúde, nas quais detalha a política pública, expondo as intenções dos formuladores. Os dados foram categorizados e estudados por meio de análise de conteúdo.

\section{A Política Nacional de Humanização segundo o Ministério da Saúde}

A Política Nacional de Humanização foi criada em 2003 pelo Ministério da Saúde, com o objetivo de solucionar os problemas da desvalorização e da falta de treinamento, em relação ao tratamento subjetivo, dos profissionais da saúde. Além disso, propunha-se a modificar a gestão centralizada e verticalizada que desincentiva o envolvimento dos trabalhadores e dos usuários (BRASIL, 2013a).

Humanização, nos termos da política, significa a valorização dos trabalhadores, dos usuários e dos gestores, cedendo uma maior autonomia nas ações e decisões relacionadas aos serviços oferecidos pelo SUS (BRASIL, 2013a). O entrosamento de todas as partes envolvidas levaria ao fortalecimento dos vínculos entre esses atores, aproximando-os e facilitando a identificação, por parte dos gestores, das necessidades da população atendida. Melhorias no local e nas condições de trabalho também fazem parte do plano da política, uma vez que deixariam os profissionais mais à vontade e satisfeitos com o seu emprego, servindo de incentivo para um aumento na qualidade do atendimento (BRASIL, 2013b).

As diretrizes gerais para a implementação da política são:

a) promover a gestão participativa por meio da ampliação do diálogo entre os profissionais, entre os profissionais e a população, entre os profissionais e a administração;

b) implantar, estimular e fortalecer grupos de trabalho de humanização. Eles funcionarão "como dispositivos de articulação, estímulo, valorização e formulação de políticas de humanização [...]" (BraSIL, 2004, p. 12);

c) estimular práticas resolutivas, racionalizar e adequar o uso de medicamentos;

d) reforçar o conceito de clínica ampliada: compromisso com o sujeito e seu coletivo, estímulo a diferentes práticas terapêuticas e corresponsabilidade de gestores, trabalhadores e usuários no processo de produção de saúde;

e) sensibilizar as equipes de saúde em relação ao problema da violência intrafamiliar e quanto à questão dos preconceitos na hora da recepção e dos encaminhamentos;

f) adequar os serviços ao ambiente e à cultura local, respeitando a privacidade e promovendo uma ambiência acolhedora e confortável; 
g) viabilizar a participação dos trabalhadores nas unidades de saúde por meio de colegiados gestores;

h) implementar um sistema de comunicação e de informação que promova o autodesenvolvimento e amplie o compromisso social dos trabalhadores de saúde;

i) promover ações de incentivo e valorização da jornada integral ao SUS, do trabalho em equipe e da participação em processos de educação permanente que qualifiquem a ação e a inserção dos trabalhadores na rede SUS.

\section{A implementação da Política Nacional de Humanização nas unidades básicas de saúde de Porto Alegre}

Neste tópico apresentaremos os dados coletados nas 25 entrevistas realizadas com coordenadores de UBS. Inicialmente, faremos uma descrição da implementação da política. O objetivo é averiguar o desenho da política resultante do processo de sua execução. Em seguida, buscaremos compreender esse processo a partir das variáveis explicativas selecionadas.

Primeiramente, traçamos o perfil dos profissionais das unidades básicas de saúde entrevistados, conforme formação profissional, sexo e tempo de serviço. No que se refere à formação profissional, 12 dos respondentes são formados em enfermagem, 10 são médicos, dois têm formação em serviço social e um em nutrição. Desses, há 21 mulheres e quatro homens; são mulheres seis profissionais da medicina, e todos os profissionais da enfermagem. Em relação ao tempo de serviço, cinco dos respondentes possuem até três anos de serviço e 18 possuem entre sete e 18 anos $^{5}$. Dessa forma, nosso grupo de informantes é formado, principalmente, por enfermeiras que trabalham em unidades de saúde há mais de sete anos. Quanto à implementação da política nas UBS, trabalhamos com duas questões: a participação no Grupo de Trabalho de Humanização (GTH) e a execução de ações relacionadas à PNH.

Os GTH são uma das principais ferramentas de implementação da PNH. Eles seriam organizados no nível das gerências distritais e teriam por objetivo difundir e incentivar a implementação da política. Ainda que a política defenda uma perspectiva de gestão compartilhada, participam do grupo somente os representantes das unidades.

\footnotetext{
${ }^{5}$ Houve a perda de duas respostas.
} 
Averiguamos que, embora os GTH já estivessem instituídos nas gerências distritais pesquisadas, nove entrevistados disseram não saber de sua existência, um afirmou que ele não existia e 15 relataram conhecer o grupo. Desses, apenas quatro participavam pessoalmente. Nos demais casos, eram outros funcionários que representavam a unidade. $O$ envio de representantes para os grupos foi uma exigência da gerência distrital.

Os trabalhadores indicados para participar dos grupos em substituição ao coordenador foram escolhidos com base em diferentes critérios, entre os quais: decisão da gerência distrital, afinidade com a ideia difundida de "humanização" (ou seja, os profissionais vistos como amáveis e, assim, mais propensos a "humanizar"), falta de afinidade com a ideia difundida de humanização (ou seja, os profissionais vistos como intratáveis e, assim, mais propensos a serem "humanizados") e disposição do trabalhador.

Cabe investigar se, nos casos em que há participação, os GTH são efetivos no alcance de seus objetivos de difundir e incentivar a implementação da política. Para atingir tais objetivos, espera-se que os participantes repassem os assuntos tratados no GTH nas reuniões de equipe realizadas em suas unidades. Nesse sentido, os informantes foram questionados quanto aos temas das reuniões. Nenhum deles soube explicar ou especificar os temas debatidos. Isso sugere que os participantes não estariam difundindo os assuntos tratados em suas unidades.

Dada a situação acima descrita, surpreendeu o fato de que 23 informantes afirmaram que a UBS na qual atuavam executava pelo menos uma ação de humanização. Se os GTH são os instrumentos de difusão da política e seu funcionamento é deficiente, o que explica a propagação da PNH?

O que ocorreu não foi, propriamente, a implementação da PNH conforme previsto em sua formulação, mas a apropriação e a reformulação da política por seus executores. Na verdade, os coordenadores expressaram uma concepção bastante ampla e variada da política e de suas ações.

A ação mais disseminada nas UBS foi o acolhimento, citado por 14 coordenadores. Contudo duas observações devem ser feitas. Essa ação é sempre adaptada às condições das unidades e, por isso, diferentes atividades são chamadas de "acolhimento", por exemplo: "tudo o que é feito na recepção", tratar os usuários com afeto, "olhar para eles de forma diferente", ouvir e conversar com usuários e/ou resolver os seus problemas, comemorar aniversários de funcionários. Em segundo lugar, essa grande referência ao acolhimento se deve ao fato de que essa ação teve a primeira tentativa de implementação em 2001, mas, segundo os informantes que passaram pelo processo, não obteve sucesso. O Ministério da Saúde apresenta o acolhimento como uma das principais diretrizes 
da PNH em 2008. Assim, essa é a ação mais conhecida pelos informantes, que acabam tomando-a como sinônimo de política de humanização .

Ao todo, foram citadas 20 diferentes atividades executadas que os entrevistados enquadraram como "política de humanização": visita domiciliar, grupos de informação e prevenção (gestantes, dependentes químicos, diabete, asma), festas internas (almoços, comemoração de aniversários), ambiência (decoração da unidade para campanhas, pintura de paredes), reunião de equipe, busca ativa (procedimento técnico de ação em vigilância epidemiológica), sala de espera (ação que utiliza o espaço da sala de espera para dar informações sobre saúde), testes rápidos (DST, HIV, gravidez), Programa Pra-nenê (vigilância da saúde das crianças no primeiro ano de vida), educação permanente, saúde do trabalhador, participação em capacitações promovidas pela SMS, visitas a escolas e asilos, realização de palestras em escolas (a pedido), ouvir o usuário, qualquer ação realizada na recepção, assistência ao direito da mulher, oferta de consulta de psiquiatria e, ainda, mudança de comportamento.

Algumas dessas atividades fazem parte da rotina das UBS, precedendo a PNH, por exemplo: reuniões de equipe, grupos de informação e prevenção, participação em capacitações, visita domiciliar, Programa Pra-nenê. Outras dificilmente podem ser inseridas na categoria "atividade": ouvir o usuário, mudança de comportamento, qualquer ação que se faz na recepção. A diversidade é um dado importante, assim como a indicação de afazeres rotineiros ou vagos.

Além disso, iniciativas como visitas a escolas e asilos, busca ativa e assistência ao direito da mulher são respostas às características do território e da população residente. As situações de busca ativa relatadas, por exemplo, eram iniciativas voluntárias dos profissionais, que, utilizando seus próprios veículos, visitavam pessoas com dificuldade de locomoção ou com doenças contagiosas que, por algum motivo, não compareceram à consulta agendada. $O$ atendimento de "assistência ao direito da mulher" era uma iniciativa de uma enfermeira que tinha conhecimento sobre procedimentos administrativos auxiliares dirigidos às

\footnotetext{
${ }^{6}$ Acolhimento é o "processo constitutivo das práticas de produção e promoção de saúde que implica responsabilização do trabalhador/equipe pelo usuário, desde a sua chegada até a sua saída. Ouvindo sua queixa, considerando suas preocupações e angústias, fazendo uso de uma escuta qualificada que possibilite analisar a demanda e, colocando os limites necessários, garantir atenção integral, resolutiva e responsável por meio do acionamento/articulação das redes internas dos serviços (visando à horizontalidade do cuidado) e redes externas, com outros serviços de saúde, para continuidade da assistência quando necessário." (BRASIL, 2008, p. 51).
} 
mulheres em situações de risco ou violência. Nada disso era previsto pela SMS, nem constava claramente nas tarefas a serem desenvolvidas ou, muito menos, fazia parte da PNH. Contextualmente, foram atividades formuladas e implementadas para dar conta das necessidades locais. Desse modo, se, por um lado, o produto do voluntarismo é a aparente falta de padrão na implementação, por outro, se trata da apropriação e do controle do trabalho e das prioridades, específicos a cada lugar, por parte da burocracia implementadora.

Também chama a atenção que nenhum respondente tenha citado ações de cogestão e que os usuários sejam sempre referidos do ponto de vista assistencial. A gestão foi referida por três coordenadores na forma de reuniões da equipe de profissionais de saúde.

Cremos que aqui há um problema de desenho da política. Do ponto de vista do gestor federal, a participação dos usuários na gestão dos serviços é uma medida para incrementar a efetividade. Contudo, do ponto de vista do profissional de saúde, que também é gestor de serviço e cujo trabalho consiste em interações diárias com os cidadãos, compartilhar sua autoridade com seus "pacientes" é um processo de perda de poder e de criação de incertezas na consecução de seu trabalho. Percebemos que há um esforço dos profissionais para, ao mesmo tempo, manter uma relação cordial - que sugere um grau de aproximação - e profissional, que exigiria certo distanciamento de seus "pacientes". Provavelmente por isso, não percebemos nenhum grau de compartilhamento de tarefas de gestão nas relações cotidianas das UBS, como ensejaria a $\mathrm{PNH}$, embora os coordenadores ouçam diariamente as demandas dos usuários e precisem lidar com a pressão direta deles - situação que não é vivenciada pelos gestores municipais e, menos ainda, pelos gestores federais.

Percebemos que a implementação da política ocorreu por meio da apropriação local e ampla das ações propostas. A seguir, apresentaremos os dados referentes às variáveis explicativas, anteriormente descritas.

A variável "conhecimento e entendimento da política pública" foi operacionalizada por meio das subvariáveis conhecimento da política, acesso e fonte de material informativo, acesso a treinamento e entendimento dos objetivos e das estratégias da política.

O que consideramos "conhecer a política" incluiu desde "ter ideia" até "conhecer os objetivos e as diretrizes". Nessa abrangência, 24 respondentes relataram conhecer a política de humanização, sendo que 15 foram informados em reuniões com as gerências distritais, cinco em cursos de capacitação ofertados pela Secretaria Municipal de Saúde sobre temas diversos relacionados à assistência à saúde, e quatro receberam informações de fontes variadas (tarefas de docência, 
propaganda veiculada na mídia televisiva, capacitação em hospital que trabalhava anteriormente, estudando para concurso público). De forma geral, a principal fonte de difusão da política pareceu ser a gerência distrital, que, a partir da exigência de criar os grupos de trabalho de humanização, passou a solicitar que os coordenadores indicassem um representante da unidade nesse fórum.

No que tange ao acesso dos coordenadores a material informativo e treinamento, dos 24 respondentes que conhecem a política, nove informaram ter recebido material informativo, 13 relataram não ter recebido e dois não lembram. Consideramos material informativo todo material que contivesse alguma explicação sobre princípios, objetivos e estratégias da política pública. As fontes de oferta desse material são variadas: pesquisa voluntária na internet, cursos, email, folheto, Conferência Nacional de Saúde e Comitê Municipal de Humanização.

Entendemos como treinamento desde curso de capacitação até palestras. Dos 24 respondentes que afirmaram conhecer a política pública, oito receberam treinamento (seis da SMS e dois de hospitais privados) e 16 não receberam. Os cursos ofertados por hospitais privados versaram sobre o Sistema Único de Saúde de forma geral. Os temas dos treinamentos ofertados pela SMS foram acolhimento e outras políticas ou procedimentos assistenciais. Somente um coordenador recebeu treinamento especificamente sobre a política de humanização. Esse informante foi encarregado da implantação do Grupo de Trabalho de Humanização em uma das gerências distritais de saúde.

A partir de 2006, a SMS passou a solicitar a inserção das atividades de humanização nos relatórios de gestão das UBS, instrumento de prestação de contas. Dessa maneira, por um lado, os coordenadores deveriam implementar ações de humanização nas UBS; por outro, tiveram pouco ou nenhum acesso ao conteúdo da política. Esse contexto é propício para a apropriação e a reformulação da política.

Se atentarmos para os objetivos e as estratégias da política, segundo a visão dos atores entrevistados, veremos que um processo de reformulação ocorreu. Quando indagados sobre os objetivos, os 24 respondentes que informaram conhecer a política apresentaram uma série de questões que agrupamos a partir de duas ênfases - objetivos com foco no usuário ou no trabalhador -, ambas distribuídas em 18 diferentes citações.

Relacionados ao usuário, os coordenadores consultados mencionaram 11 diferentes objetivos. Os mais citados se pautaram no atendimento (melhorar atendimento, tornar mais resolutivo, tornar mais personalizado, tornar mais humano, atender com equidade e tornar mais afetivo) e no acolhimento. Os demais são: melhorar o acesso aos serviços de saúde, olhar de forma diferente para os usuários, educar o usuário no que se refere ao funcionamento do SUS e das unidades de saúde e humanizar os partos para diminuir o número de cesáreas. 
Com ênfase nos trabalhadores, sete diferentes objetivos foram atribuídos à política: melhoria da estrutura física dos prédios com a criação de espaço de descanso, melhoria das práticas de trabalho, incremento das condições de trabalho, melhoria do clima de trabalho, integração dos funcionários, acolhimento do trabalhador e humanização do servidor.

Uma vez mais, pode-se observar que os atores não compartilham do mesmo entendimento quanto aos objetivos da política, e também é possível questionar a atribuição de estatuto de objetivos a questões como: tornar o atendimento mais humano ou olhar de forma diferente para os usuários. Em meio à diversidade de "objetivos" citados, percebemos a interpretação livre e subjetiva da política, a partir do que sugere seu nome: humanização. Mesmo porque foi comum o uso de termos como afeto, humano, olhar, educação, personalizar. Esses são, na percepção dos entrevistados, relacionados com a palavra "humanizar". Dessa forma, embora os objetivos citados não constem diretamente como alvo da PNH, de forma geral, e considerando as proposições extremamente amplas e vagas da política, eles acabam sendo concebidos como tal.

A diversidade de objetivos se expressa na variedade de estratégias citadas. Vinte e um atores apontaram 14 diferentes estratégias para alcançar os objetivos da política, e quatro informantes não souberam responder. $\mathrm{O}$ acolhimento aparece como a ação mais citada, sendo que 11 informantes o consideraram a forma de operacionalização da política. Além do acolhimento, tivemos: melhorar estrutura física (sala de espera e sala de acolhimento), educação permanente e saúde do trabalhador, reformular marcação de consultas (eliminar ou aumentar a oferta), conscientização dos usuários do funcionamento da UBS e suas limitações, promover eventos festivos com funcionários, mudar comportamento dos profissionais, mudar metodologia de trabalho, envolver todos os profissionais, trabalhar com o Conselho Municipal de Saúde, garantir os direitos dos usuários, gestão compartilhada pela equipe de profissionais da saúde, implantar o Grupo de Trabalho de Humanização e conversar.

Algumas estratégias são muito gerais, assemelhando-se a princípios (garantir os direitos dos usuários) ou objetivos (mudar o comportamento dos profissionais). Outras são mais operacionalizáveis: promover eventos festivos, implantar o Grupo de Trabalho de Humanização. Além disso, o acolhimento apareceu como objetivo e estratégia. Observa-se que não há entendimento compartilhado sobre a questão, nem clareza quanto à relação entre objetivos e estratégias.

No que se refere à variável "condições organizacionais", consideramos a estrutura física da unidade de saúde e a percepção sobre qualidade dos recursos humanos. 
Os dados sobre a estrutura física das unidades de saúde foram coletados a partir da observação. Recebeu atenção o aspecto geral dos prédios, como a existência ou não de infiltrações, pintura das paredes, tamanho das salas de atendimento e de espera. Esse último espaço figura com importância no plano da política pública, pois, ao lado da fila, é lugar privilegiado de primeiro contato entre os usuários e o sistema de saúde. Sua estrutura pareceria apontar para uma maior ou menor aderência das unidades aos objetivos da política.

Foram utilizados os seguintes critérios de classificação:

- ótima estrutura física: prédio novo ou reformado, sala de espera ampla, podendo ter cadeiras com encosto, TV, revistas e brinquedos;

- boa estrutura física: prédio novo ou reformado, sala de espera pequena ou sem sala de espera;

- estrutura física regular: prédio com infiltrações, problemas no forro e/ou piso, sala de espera pequena ou sem sala de espera, salas de atendimento pequenas;

- estrutura precária: unidade funcionando de forma improvisada em local não adequado para o desenvolvimento dos serviços.

Classificamos sete unidades na categoria "estrutura física ótima", localizadas em prédios novos ou recém-reformados, com sala de espera ampla e, algumas, com aparelho de televisão, livros, revistas e brinquedos. Nove unidades tiveram suas estruturas físicas classificadas como "boas", pois, embora o prédio também fosse novo ou reformado, a sala de espera era pequena (sete unidades) ou não existia (duas unidades). Nessas, os usuários esperavam na parte externa da UBS ou nos corredores. Na categoria "regular", classificamos sete UBS, já que os prédios apresentavam infiltrações e/ou deficiência no piso e no forro. Em duas dessas UBS, a sala de espera era ampla, sendo que numa delas havia equipamentos desativados empilhados nos cantos; duas unidades possuíam sala de espera pequena; e três sequer a possuíam. Por fim, encontramos duas unidades funcionando de forma improvisada, já que seu prédio estava em reforma. Essas estavam em situação extremamente precária, sujas, ou não havia sequer pias para lavar as mãos.

A maioria das unidades visitadas (16) estava em condições boas ou ótimas. Entretanto deve-se ressaltar que as reformas feitas priorizaram as áreas voltadas para a assistência. Espaços para refeições, descanso e reuniões para os funcionários ainda são raros, o que é contraditório com o objetivo de valorização do trabalhador contido na PNH. Com isso, parece não haver relação entre as condições físicas da unidade e a implementação de ações relacionadas à política de humanização. 
No que se refere à percepção sobre a qualidade dos recursos humanos necessários para desempenhar as atividades, encontramos o seguinte quadro: 17 coordenadores de UBS consideravam que os recursos (médicos, enfermeiros e pessoal administrativo) disponíveis em suas unidades eram insuficientes para as atividades que precisariam ser executadas. Soma-se a isso a percepção da falta de treinamento, seja voltado para procedimentos técnicos, seja para desenvolver habilidades de comunicação e interação com colegas e usuários. Por outro lado, oito atores informaram que a qualidade dos recursos humanos seria adequada à demanda da unidade.

A questão dos serviços administrativos interfere de forma importante na rotina dos profissionais. Não há previsão de trabalhadores administrativos no quadro de pessoal das UBS. Esses serviços são realizados pelos profissionais de enfermagem e, em alguns casos, com o auxílio dos seguranças-porteiros. Esses agem prestando informações sobre o funcionamento das unidades e/ou atendendo ao telefone. Os trabalhadores da limpeza e da segurança são terceirizados, e sua participação nas atividades administrativas é voluntária. Dessa forma, a execução dessas atividades varia muito entre as UBS.

Salienta-se que não houve acréscimo de recursos relativos à política - são as mesmas pessoas, com a mesma carga horária e com uma rotina já estabelecida. Portanto as UBS deveriam dar conta das tarefas anteriores reconfiguradas à luz da PNH.

Para tratar da relação entre as condições organizacionais e a implementação, devemos lembrar que as ações implementadas e os objetivos atribuídos à PNH foram reformulados pelos implementadores, permitindo lidar com os constrangimentos percebidos. Bem por isso, a influência das condições organizacionais sobre a implementação se mostrou fraca.

Por fim, a variável "conformidade dos implementadores com os princípios e os objetivos da política" foi operacionalizada, principalmente, por meio da visão dos respondentes acerca da política pública. Em primeiro lugar, 17 respondentes entendiam que a política de humanização não estaria adequada à realidade de constrangimentos e limitações em que operam as unidades de saúde. De acordo com essa visão, as UBS não contavam com espaços adequados para fazer o primeiro atendimento ("sala de acolhimento", espaço para indagar o usuário sobre sua saúde com privacidade) e com trabalhadores suficientes para realizar esse atendimento da forma como deveria (segundo a visão disseminada, o acolhimento exigiria mais tempo de conversa com o usuário).

Em segundo lugar, sete atores enfatizaram questões que versam sobre a clareza e a relevância da política pública. A política é considerada subjetiva, de difícil operacionalização ou, ainda, utópica. Também pudemos perceber certo desconcerto 
quanto à ideia de uma política que propõe humanizar um serviço prestado por seres humanos a humanos. Além de colocar em xeque certa identidade humanista, os problemas de funcionamento dos serviços passariam a ser decorrentes do comportamento dos trabalhadores, e não da carência de recursos.

Apenas um coordenador respondeu que considera a política adequada às necessidades da unidade básica de saúde. Os demais estavam pessimistas e não a viam como uma iniciativa que pudesse solucionar as dificuldades que enfrentam ou melhorar seu trabalho. Esse quadro apontou para um baixo grau de apoio à política. De fato, sua execução não foi aquela formulada pelo Ministério da Saúde. Vimos que a PNH foi interpretada e reformulada. O resultado desse processo foi a política pública efetivamente implementada. Assim, podemos corroborar a literatura no que diz respeito à relação entre apoio à política e sua efetiva implementação. Em nosso caso, a visão negativa dos coordenadores sobre a PNH, a socialização inexistente e os constrangimentos operacionais prejudicaram a implementação da política formulada pelo Governo Federal. Em compensação, houve redirecionamento da implementação da política de humanização, enquanto formulação realizada pela burocracia de nível de rua.

\section{A Política Nacional de Humanização segundo a burocracia implementadora}

A relação entre a política pública formal e a política pública implementada, com a qual o cidadão se relaciona, é um tema que paira sobre o campo da análise da implementação de políticas públicas desde a afirmação, de Pressman e Wildavsky (1984), de que o verbo implementar precisa ter como objeto uma política pública. Aceita-se que tal relação não é de determinação e que o plano sofre modificações durante sua execução, assim como também influencia as ações e decisões dos implementadores.

Foi justamente isso que averiguamos em nosso estudo. Uma relação bastante fraca entre a ação dos implementadores e o plano. Esse é pouco estruturado, seus objetivos não estão claros, bem como as formas de alcançá-los, e não houve socialização. Essas características abrem espaço para a agência dos implementadores, pois, como apontam Majone e Wildavsky (1984), políticas públicas abstratas estão sujeitas a muitas incertezas e contêm mundos possíveis de aplicações práticas: quanto mais geral uma ideia, mais provável que ela seja realizada de forma diversa daquela pensada pelos formuladores.

A ideia de humanizar os serviços de saúde foi apropriada pela burocracia implementadora, que promoveu a seguinte adaptação: redefiniu as atividades da humanização, que, em vez de surgirem na forma de novas tarefas a serem 
desenvolvidas, se transformaram em rótulos aplicados a atividades previamente existentes. Com isso, esses atores construíram uma política que diferia bastante da proposta dos formuladores. Temos duas questões aqui.

Primeiro, diante da frouxidão das definições, da carência de treinamento, das limitações percebidas no contexto organizacional e da exigência formal de que fossem executadas ações de humanização, os implementadores construíram uma ideia ampla e não compartilhada da política. Isso permitiu o seguinte ajuste: atividades que já faziam parte da rotina das unidades foram recategorizadas como ações da política de humanização. Com isso, os atores cumpriam com uma exigência formal da SMS, recheando seus relatórios de atividades com ações da nova política. Como afirma um respondente, "tem um monte de coisas que a gente faz que é humanização e nós não sabíamos". Tal movimento permitiu lidar com o gap entre objetivos e realizações, moldando os objetivos ao que pode ser feito ou ao que já era feito. Desse modo, a adaptação da política minimizou a carência percebida de recursos e possibilitou a implementação.

Nota-se que as condições organizacionais moldam as práticas dos atores. Assim, o processo de adaptação é resultado das decisões e ações dos atores implementadores frente aos incentivos organizacionais (BRODKIN, 2011).

Segundo, é essa reformulação que permite dizer que a Secretaria Municipal da Saúde de Porto Alegre implementa a Política Nacional de Humanização. Esse processo de implementação/adaptação/formulação demonstra que, apesar das falhas de desenho, o plano da política exerce influência nos espaços locais. Nesse caso, isso ocorreu por meio da ideia preconcebida de "humanização" e da solicitação da SMS de que "ações de humanização" fossem inseridas nos relatórios de gestão das unidades.

A adaptação da PNH aos contextos locais possibilitou aos implementadores resolver três problemas: atender às demandas da autoridade central, manter a rotina funcionando e evitar conflitos com funcionários (que são comuns quando novas atividades são adicionadas à rotina). Assim, foi interessante atentar para a especificidade do trabalho dos coordenadores, que interagem com os demais trabalhadores de saúde, com a gerência distrital e com os usuários. Recebem e atendem demandas nessas três frentes. Tal conformação expressa um grau elevado de discricionariedade no desempenho de suas funções. A discricionariedade funcionou como um mecanismo de adaptação e, também, de formulação. $E$ a adaptação pode ser vista como um processo de correção de erros de desenho e de acomodação de diferentes demandas e necessidades.

Observou-se também que tanto as ações desenvolvidas quanto os objetivos e estratégias atribuídos à política enfatizavam a assistência, afastando-se das 
intenções dos formuladores e indicando um não compartilhamento de preferências com as instâncias gestoras do sistema. Nesse quadro, Méier e O'Tolle (2006 apud Lotta, 2012a) consideram que o processo de tomada de decisão do burocrata de nível de rua teria como referência sua representatividade perante os cidadãos, "suas ações se encaixam nos valores que compartilha com o público" (LotTA, 2012a, p. 37). Isso pode ser decorrência da própria natureza do trabalho no setor de saúde, no qual os serviços são produzidos por meio da interação entre profissional e "paciente".

A dinâmica de implementação da política pública estudada apontou para a importância da burocracia implementadora como variável explicativa da trajetória e da conformação do processo, assim como da política efetivada. O espaço de execução apareceu como lócus de criação de objetivos e estratégias, expressando o poder decisório desses atores.

A discricionariedade permitiu a implementação da política. No entanto esse mesmo mecanismo garantiu que o produto da execução fosse diverso de seu planejamento inicial. Esse foi o paradoxo que encontramos em nosso estudo.

Vimos implementadores que decidem, formulam e disputam o controle de seu espaço de atuação com outros níveis hierárquicos e, inclusive, com outros níveis de governo. A partir disso, podemos definir a implementação como um processo de apropriação de uma ideia que, nesse sentido, é consequência da interação entre a intenção (expressa no plano) e os elementos dos contextos locais de ação. Em nosso estudo, formulação e implementação mesclam-se por meio das percepções, decisões e ações da burocracia implementadora.

Os resultados apontam que a burocracia não apenas responde aos incentivos centrais, como os adapta, criando práticas informais que respondem pelo sucesso da política.

\section{Considerações finais}

A burocracia responsável pela implementação da Política Nacional de Humanização dos Serviços de Saúde construiu um conjunto de ideias peculiares a respeito da política. A amplitude e a multiplicidade dessas percepções foram facilitadas pela ausência de uma socialização desses atores nos marcos da política. Contudo, a partir da leitura da estrutura normativa da política pública, podemos dizer que ela própria é pouco estruturada. Em segundo lugar, diante da exigência de que executassem ações de humanização, os atores foram adaptando as atividades tradicionalmente desenvolvidas a suas respectivas compreensões do que fosse a política. Com isso, temos uma situação interessante: apesar da carência 
de treinamento e de pessoal, bem como do entendimento difuso e múltiplo dos objetivos e das estratégias, praticamente todas as unidades implementaram algum tipo de "política de humanização". Usamos aspas para enfatizar que a política será diferente conforme a compreensão que têm os atores sobre ela. Dessa forma, a política se tornou uma categoria de entendimento eminentemente local. Ela deixou de ser uma política pública do Ministério da Saúde e passou a ser uma política pública do implementador.

\section{Referências bibliográficas}

BASTIEN, J. Goal ambiguity and informal discretion in the implementation of public policies: the case of Spanish immigration policy. International Review of Administrative Sciences, v. 75, n. 4, 2009.

Brasil. Ministério da Saúde. HumanizaSUS - Política Nacional de Humanização: a humanização como eixo norteador das práticas de atenção e gestão em todas as instâncias do SUS. Brasília: Editora do Ministério da Saúde, 2004.

. Ministério da Saúde. HumanizaSUS: documento-base para gestores e trabalhadores do SUS. Brasília: Editora do Ministério da Saúde, 2008.

Ministério da Saúde. Política Nacional de Humanização. Brasília:

Ministério da Saúde, 2013a. Disponível em: <http://portal.saude.gov.br/portal/ saude/cidadao/area.cfm?id_area=1342>. Acesso em: 12 mar. 2013.

Ministério da Saúde. O que é a Política Nacional de Humanização.

Brasília: Ministério da Saúde, 2013b. Disponível em: <http://portal.saude.gov.br/ portal/saude/cidadao/visualizar_texto.cfm?idtxt=28288>. Acesso em: 12 mar. 2013.

BRODKIN, E. Z. Bureaucracy redux: management reformism and the welfare state. Journal of Public Administration Research and Theory, n. 17, 2007.

Policy work: street-level organizations under new managerialism. Journal of Public Administration Research and Theory, n. 21, 2011.

FARIA, C. A. Implementação: ainda o "elo perdido" da análise de políticas públicas no Brasil? In: FARIA, C. A. (Org.). Implementação de políticas públicas: teoria e prática. Belo Horizonte: Editora PUC Minas, 2012. p. 123-152.

Gofen, A. Mind the gap: dimensions and influence of street-level divergence. Journal of Public Administration Research and Theory, n. 24, 2014.

HuPE, P. What happens on the ground: persistent issues in implementation research. Public Policy and Administration, v. 29, n. 2, 2014.

HuPE, P.; HILL, M.; NANGIA, M. Studying implementation beyond deficit analysis: the top-down view reconsidered. Public Policy and Administration, v. 29, n. 2, 2014.

LIPSY, M. Street-level Bureaucracy: dilemmas of the individual in public services. New York: Russel Sage Foundation, 1980. 
LotTA, G. S. O papel das burocracias do nível de rua na implementação de políticas públicas: entre o controle e a discricionariedade. In: FARIA, C. A. (Org). Implementação de políticas públicas: teoria e prática. Belo Horizonte: Editora PUC Minas, 2012a. p. 20-49.

Desvendando o papel dos burocratas de nível de rua no processo de implementação: o caso dos agentes comunitários de saúde. In: FARIA, C. A. (Org). Implementação de políticas públicas: teoria e prática. Belo Horizonte: Editora PUC Minas, 2012b. p. 221-259.

LunDIN, M. When does cooperation improve public policy implementation? The Policy Studies Journal, v. 53, n. 4, 2007.

Majone, G.; Wildavsky, A. Implementation as evolution. In: Pressman, J. L.; Wildavsky, A. Implementation. California: University of California Press, 1984. p. 163-180.

May, P. J. Policy design and implementation. In: Peters, B. G.; Pierre, J. The SAGE Handbook of Public Administration. London: SAGE, 2012. p. 279-291.

MAY, P. J.; WINTER, Soren C. Politicians, managers, and street-level bureaucrats: influences on policy implementation. Journal of Public Administration Research and Theory, n. 19, 2009.

Mazmanian, D. A.; Sabatier, P. A. Implementation and Public Policy. Glenview: Scott, Foresman Company, 1983.

PIREs, R. R. C. Estilos de implementação e resultados de políticas públicas: fiscais do trabalho e o cumprimento da lei trabalhista no Brasil. Dados, Rio de Janeiro, v. 52, n. 3, 2009.

. Burocracias, gerentes e suas "histórias de implementação": narrativas do sucesso e fracasso de programas federais. In: FARIA, C. A. (Org). Implementação de políticas públicas: teoria e prática. Belo Horizonte: Editora PUC Minas, 2012. p. 182-220.

Pressman, J. L.; Wildavsky, A. Implementation. Berkeley: University of California, 1984. SAETREN, H. Facts and myths about research on public policy implementation: outof-fashion, allegedly dead, but still very much alive and relevant. The Policy Studies Journal, v. 33, n. 4, 2005.

Implementing the third generation research paradigm in policy implementation research: an empirical assessment. Public Policy and Administration, v. 29, n. 2, 2014.

Soss, J.; Fording, R.; SCHRAM, S. F. The organization of discipline: from performance management to perversity and punishment. Journal of Public Administration Research and Theory, n. 21, 2011.

TUMmeRs, L. Explaining the willingness of public professionals to implement new policies: a policy alienation framework. International Review of Administrative Sciences, v. 77, n. 3, 2011.

Winter, S. Implementation. In: Peters, B. G.; Pierre, J. The SAGE Handbook of Public Administration. London: SAGE, 2014. p. 227-236. 
Luciana Leite Lima

Doutora em Ciências Sociais pela Unicamp e Professora do Departamento de Sociologia da Universidade Federal do Rio Grande do Sul. Contato: lucianaleitelima@gmail.com

Luciano D’Ascenzi

Doutor em Ciências Sociais pela Unicamp e Técnico Superior da Agência Estadual de Regulação dos Serviços Públicos Delegados do Rio Grande do Sul. Contato: luciano.dascenzi@gmail.com

Gianna Vargas Salgado Dias

Graduanda do bacharelado em Políticas Públicas da Universidade Federal do Rio Grande do Sul. Contato: gianna.vargas@ufrgs.br

Renata Bruscatto

Graduanda do bacharelado em Políticas Públicas da Universidade Federal do Rio Grande do Sul. Contato: resbruscato@hotmail.com 
RSP 